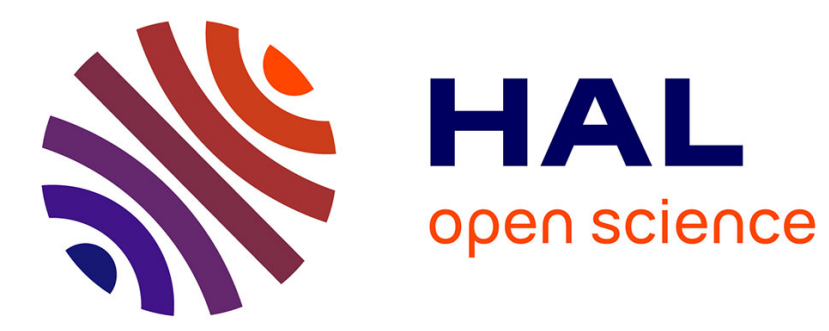

\title{
High temporal resolution SO2 flux measurements at Erebus volcano, Antarctica
}

\author{
Marie Boichu, Clive Oppenheimer, Vitchko Tsanev, Philip R. Kyle
}

\section{To cite this version:}

Marie Boichu, Clive Oppenheimer, Vitchko Tsanev, Philip R. Kyle. High temporal resolution SO2 flux measurements at Erebus volcano, Antarctica. Journal of Volcanology and Geothermal Research, 2009, 190, pp.325-336. 10.1016/j.jvolgeores.2009.11.020 . hal-01157827

\section{HAL Id: hal-01157827 \\ https://hal.science/hal-01157827}

Submitted on 28 May 2015

HAL is a multi-disciplinary open access archive for the deposit and dissemination of scientific research documents, whether they are published or not. The documents may come from teaching and research institutions in France or abroad, or from public or private research centers.
L'archive ouverte pluridisciplinaire HAL, est destinée au dépôt et à la diffusion de documents scientifiques de niveau recherche, publiés ou non, émanant des établissements d'enseignement et de recherche français ou étrangers, des laboratoires publics ou privés. 


\title{
High temporal resolution $\mathrm{SO}_{2}$ flux measurements at Erebus volcano, Antarctica
}

\author{
Marie Boichu ${ }^{\mathrm{a}}$, Clive Oppenheimer ${ }^{\mathrm{a}}$, Vitchko Tsanev ${ }^{\mathrm{a}}$, Philip R. Kyle \\ ${ }^{a}$ Department of Geography, University of Cambridge, Downing Place, Cambridge CB2 \\ 3EN, United Kingdom \\ ${ }^{b}$ Department of Earth and Environmental Science, New Mexico Institute of Mining and \\ Technology, Socorro, NM 87801, USA
}

\begin{abstract}
The measurement of $\mathrm{SO}_{2}$ flux from volcanoes is of major importance for monitoring and hazard assessment purposes, and for evaluation of the environmental impact of volcanic emissions. We propose here a novel technique for accurate and high time resolution estimations of the gas flux. We use two wide field of view UV spectrometers capable of collecting, instantaneously, light from thin parallel cross sections of the whole gas plume, obviating the need for either traversing, scanning or imaging. It enables tracking of inhomogeneities in the gas cloud from which accurate evaluation of the plume velocity can be made by correlation analysis. The method has been successfully applied on Mt. Erebus volcano (Antarctica). It yields estimations of the plume velocity and gas flux at unprecedented time resolution $(1 \mathrm{~Hz})$ and high accuracy (uncertainty of 33\%). During a $\sim 2 \mathrm{~h}$ experiment on 26 December 2006, $\mathrm{SO}_{2}$ flux varied between 0.17 and $0.89 \pm 0.2 \mathrm{~kg} \mathrm{~s}^{-1}$ with a vertical plume velocity varying between 1 and $2.5 \pm 0.1 \mathrm{~m} \mathrm{~s}^{-1}$. These
\end{abstract}

Email addresses: mb632@cam.ac.uk (Marie Boichu), co200@cam.ac.uk (Clive Oppenheimer), vip20@cam.ac.uk (Vitchko Tsanev), kyle@nmt.edu (Philip R. Kyle) 
measurements provide insight into the short-term variations of the passive degassing of this volcano renowned for its active lava lake. A cyclicity in flux, ranging from about 11-24 min, is evident. We propose two physical mechanisms to explain this degassing pattern, associated to periodic supply of either gas-rich magma or gas alone into the lake. The dual-wide field of view DOAS technique promises better integration of geochemical and geophysical observations and new insights into gas and magma dynamics, as well as processes of magma storage and gas segregation at active volcanoes.

Key words: Volcanic degassing, DOAS spectroscopy, high time resolution gas flux

\section{1. Introduction}

2 Gas emissions from volcanoes are measured for several purposes, includ3 ing monitoring, hazard assessment, and investigation of environmental im4 pact. For over a century, fumarole chemistry has been studied using in-situ 5 collection techniques. While these yield highly detailed analysis of fluid com6 position, field access can be limited and data streams are often discontinu7 ous. However, since the first application of the correlation spectrometers 8 (COSPEC), four decades ago (Moffat and Millan, 1971; Stoiber and Jepsen, 9 1973), numerous ground-based, airborne and spaceborne optical remote sensing instruments and methods have emerged capable of measuring both volcanic gas fluxes and composition, for individual vents or an entire plume, and with improved temporal resolution (McGonigle and Oppenheimer, 2003). As a result, gas geochemistry has increasingly found its place among the operational techniques of volcano monitoring (Oppenheimer, 2003; Galle et al., 
2003). Nevertheless, the time resolution of gas measurements still lags behind what is routinely achieved in geophysical studies, limiting progress in understanding the links between seismicity, deformation and degassing that are clearly of considerable relevance for understanding volcano behavior, especially the transition to explosive activity (Fischer et al., 1994; Watson et al., 2000; Young et al., 2003). Some volcanoes clearly exhibit rapid changes in gas composition and flux related to magmatic activity. For instance, Oppenheimer et al. (2006) and Burton et al. (2007) have demonstrated pronounced compositional differences in gas emissions associated with and between Strombolian eruptions using the technique of open-path Fourier transform infrared spectroscopy. This technique enables observations at a frequency of about $1 \mathrm{~Hz}$. But achieving comparable time resolution for gas flux measurements is another challenge, since the entire plume needs to be captured.

The most widespread method used for measuring volcanic gas fluxes is scattered light ultraviolet spectroscopy (see e.g. McGonigle and Oppenheimer (2003) for a review) using correlation spectroscopy or Differential Optical Absorption Spectroscopy (DOAS). The plume is usually profiled across its transport direction from below with a zenith-viewing telescope, the apparatus being mounted on a moving vehicle, or by use of a scanning system (Fischer et al., 2002; Edmonds et al., 2003). The flux is then obtained from the product of the gas column abundance (integrated across the plume section) and the plume transport speed. The main sources of uncertainty in flux measurements made in this way are generally considered to be linked 
to light scattering processes (Millan, 1980; Mori et al., 2006; Kern et al., 2009) and to the error in the plume speed estimation (Stoiber et al., 1983; Williams-Jones et al., 2006), which is sometimes taken to be the wind speed measured or modelled close to the plume altitude. But even if wind speed is measured at the exact plume altitude, it may not represent well the plume velocity due to the complex wind-fields that develop downwind of volcanoes due to topography. Different methods have been proposed to enhance plume speed accuracies but are not yet widely used. One approach is to use multiple UV spectrometers sited at fixed positions some distance apart so as to track the transport of inhomogeneities in the plume (McGonigle et al., 2005a; Williams-Jones et al., 2006); related approaches use a single instrument carried beneath the plume, with optics that enable alternating fields of view, one at zenith, the other inclined (McGonigle et al., 2005b), or simultaneous measurements in two directions using a double spectrometer (Johansson et al., 2009). Latterly, imaging UV techniques (imaging DOAS or UV cameras combined with appropriate narrow band filters) have been demonstrated (Bobrowski et al., 2006; Bluth et al., 2007; Mori and Burton, 2006), which can achieve a high time resolution on flux measurements.

Here we propose an alternative, simple solution which is to use a system employing two UV spectrometers equipped with wide field of view telescopes that instantaneously collect light from two narrow and parallel entire cross sections of the plume (Fig. 1). This obviates the need for either traversing, scanning or imaging. We will use the acronym DW-FOV DOAS (dual wide field of view DOAS) to refer to this technique. By using two spectrometers 
with fields of view separated by a small angle, time-series of retrieved gas amounts can be correlated to obtain (through knowledge of the viewing and plume geometry) the plume transport speed through time. Such a system is capable, therefore, of accurate, highly time-resolved measurements of volcanic gas fluxes.

The aim of this paper is to describe this new instrumentation and methodology, and to apply the approach to rapid measurements of $\mathrm{SO}_{2}$ fluxes at Mt. Erebus in Antarctica. Interest in the emissions from Erebus is fuelled by the potential impact of sulfur, halogens and $\mathrm{NO}_{x}$ on the pristine atmospheric environment (Radke, 1982; Zreda-Gostynska et al., 1993, 1997; Oppenheimer et al., 2005, 2009a), but also because the volcano is renowned for its dynamic lava lake and Strombolian activity. This technique provides new possibilities to investigate the magma degassing of volcanoes that exhibit short-term variability in the dynamics of magma transport and degassing, which are reflected in changes in eruptive behavior (Oppenheimer et al., 2009b; Harris et al., 2005). Measurements are now also much more comparable in terms of frequency of data acquisition with observations provided by common geophysical tools such as seismology. At Erebus, interpretation of the observed $\mathrm{SO}_{2}$ variations in terms of magma dynamics is simplified by the limited role of hydrothermal scrubbing of emissions (Symonds et al., 2001). Moreover, observations of $\mathrm{SO}_{2}$ flux from the volcano by scanning UV spectroscopy have previously suggested a periodicity of $\sim 10$ min (Sweeney et al., 2008), which we are keen to investigate further.

After a section describing the methodology, we will present the high res- 
olution time-series of plume speed and flux obtained at Erebus. A wavelet analysis of these flux observations reveal distinctive patterns in degassing. We will discuss about their interpretation in terms of gas and magma dynamics as well as processes of magma storage and gas sequestration. Finally, three appendixes include some technical content and an electronic supplement to this article presents an animation showing the results in form of a "SO $\mathrm{SO}_{2}$ fluxmeter" superimposed on video of the plume.

\section{Methodology}

Note that all mathematical symbols used in the following are listed in Table 1.

\subsection{Experiment description}

We collected UV DOAS spectroscopic measurements at Erebus on the 26 December 2006 during conditions of clear sky and low wind, such that the plume rose approximately vertically from the crater. Spectra were recorded using two Ocean Optics USB4000 spectrometers spanning a wavelength range of about 283-440 nm, with a resolution of, respectively, 0.5 and $0.6 \mathrm{~nm}$ (FWHM). Hoya filters were used to reduce the amount of stray light. As shown in Fig. 1, each spectrometer was attached to a telescope consisting of spherical and cylindrical lenses that provide a horizontal angle of aperture $\theta_{W F O V}$ of $\sim 22^{\circ}$, giving an elongated horizontal field of view, and a narrow vertical angle of aperture $\theta_{N F O V}$ of $\sim 0.5^{\circ}$ defined by the width of the spectrometer's slit and the focal length of the positive lens. The long axis of the field of view $\left(d_{X}\right)$ was designed so that the projected $\theta_{W F O V}$ footprint (equivalent to $\sim 810 \mathrm{~m}$ at the distance of the plume of $\sim 2004 \mathrm{~m}$ here) would 
sample the entire plume. The long axes of the fields of view were parallel but displaced, so that each instrument viewed a different cross-section of the plume, determined by the observation geometry.

Spectra from each instrument were recorded on to separate laptop computers, whose clocks were synchronized using a GPS unit so as to yield a time-stamped series of data. All observations were made from Lower Erebus Hut, a horizontal distance $D$ of $\sim 1960 \mathrm{~m}$ from the summit of Erebus, and mostly viewed the vertically-rising plume during periods with very low winds. The elevation of the lowermost field of view $(\alpha)$ was $\sim 12^{\circ}$ and separation of the two fields of view $(\beta)$ was $2.0^{\circ}$, precisely adjusted thanks to a goniometer. The distance $d_{Y}$ between the two fields of view is then:

$$
d_{Y}=D\left[\tan \left(\frac{\pi}{180}(\alpha+\beta)\right)-\tan \left(\frac{\pi}{180} \alpha\right)\right]
$$
out of the plume. 


\subsection{Spectroscopic retrieval}

$\mathrm{SO}_{2}$ column amounts were retrieved following differential optical absorption spectroscopy (DOAS) procedures (Platt and Stutz, 2008). The reference spectra included in the nonlinear fit were obtained by using Windoas convolving high-resolution $\mathrm{SO}_{2}$ (293K, air) (Bogumil et al., 2003) and $\mathrm{O}_{3}$ (246K, air) (Burrows et al., 1999) cross-sections with Gaussian instrumental line shapes estimated using a mercury lamp (FWHM $=0.5$ and $0.6 \mathrm{~nm}$ for the lower and upper spectrometers, respectively). A Ring spectrum calculated using DOASIS was also included in the fit as well as a third order polynomial to remove broad band structures from measured optical densities. The same optimized fitting window (307.6-330.0 nm) was selected to analyze data from both spectrometers, yielding a near random fit residual structure with minimal standard deviation. As a result, the fit residual was between ten and twenty times smaller than the $\mathrm{SO}_{2}$ fit. Spectra recorded with the upper spectrometer are slightly noisier than those from the lower one leading to an error of a few percent higher on the retrieved column amounts. The obtained time series of the $\mathrm{SO}_{2}$ column amounts for both instruments are shown in Fig. 2.

We are using wide field of view UV spectrometers capturing instantaneously the whole horizontal plume cross-section at two different altitudes. Hence, the retrieved gas amount for one W-FOV DOAS instrument can be approximated by the mean column amount along the different directions inside the wide angle of observation, as shown in Appendix A. The relative error on this approximation (Eq. A.18) depends on plume optical densities of the studied volcano. As illustrated by Fig. 8, this relative error is of a few percent for a weak gas emitter like Erebus, and could reach in the worst 
case up to $45 \%$ for a strong gas emitter like Kilauea volcano (assuming $\mathrm{SO}_{2}$ column amounts up to $5 \times 10^{18}$ molec.cm $\left.{ }^{-2}\right)$.

\subsection{Plume speed retrieval}

Inhomogeneities, induced by turbulence or variations in volcanic degassing rate, give characteristic structures to the plume, which can be observable through the time series of the gas column amounts obtained for each spectrometer. Correlation analysis is used to estimate the transport speed of these structures, representative of the spatially averaged plume velocity over the distance separating the fields of view of each spectrometer and of the mean plume speed on the time window used for correlation.

\subsubsection{Principle of the cross correlation analysis}

Estimating the plume speed (with a time resolution of $\sim 1 \mathrm{~s}$ ) at time $t$ requires calculation of the cross correlation coefficients between segments of the two column amount time series selected using a sliding window of a given duration $\Delta T$, centred respectively in $t$ for the lower spectrometer and in $(t+\tau)$ for the upper spectrometer, where $\tau$ is the time shift between the two windows (see Fig. 4 for symbols). Cross correlation coefficients $C C F(t, \tau, \Delta T)$ consequently depend on three variables.

The time lag $\tau_{l a g}$ between the upper spectrometer signal and the lower one, corresponding to the time for an inhomogeneity to travel from the first to the second instrumental FOV, is a priori equal to the time shift, giving the absolute maximum of the cross-correlation coefficients calculated at time $t$, with $\tau$ varying in $\left[0: \Delta \tau: \tau_{\max }\right]$ where $\Delta \tau$ represents the incremental time step of the cross correlation (equal to $2 \mathrm{~s}$ here) and $\tau_{\max }$ the maximum value 
of $\tau$ associated with the minimum expected plume speed taken equal to 0.1 $\mathrm{m} \mathrm{s}^{-1}$.

Plume speed $v$ is deduced from this time lag according to the relation:

$$
v=\frac{d_{Y}}{\tau_{l a g}} .
$$

Because spectrometer's fields of view do not cross perpendicularly the plume but are slightly inclined, the distance $d_{Y}$ separating them at the entrance of the plume is a bit different than at its exit, depending on the plume depth (less than $400 \mathrm{~m}$ at Erebus which is the crater size seen by pointing from Lower Erebus Hut). This uncertainty on $d_{Y}$ is taken into account in the estimation of error on the speed, developed in the result section, by assuming an uncertainty of $\pm 50 \mathrm{~m}$ on the horizontal distance $\mathrm{D}$ between spectrometers and plume.

\subsubsection{Influence of the correlation window length}

As shown in Fig. 3a, estimated plume speeds depend on the length of the sliding correlation window, compared with the time interval between two structures in the degassing. Velocities are smoothed with a long window, while a narrow window yields estimations closer to the instantaneous plume speed. However, very low velocities obtained with the narrow window (close to $\sim 0.1 \mathrm{~m} \mathrm{~s}^{-1}$ ) do not have a physical meaning but show the limit of the correlation analysis and the need for a refinement of the method to remove them. Indeed, recurrent structures can exist in the observed degassing and lead to a periodicity in the cross correlation function, relative to the timeshift, which is more pronounced with a narrow window (Fig. 4). In this case, the speed estimated from the absolute maximum of the $C C F$ coefficients, 
over the range of $\tau$ values, can yield a match between a structure recorded at the first spectrometer, not with the time-delayed corresponding structure at the second instrument as desired, but with a translated structure resulting from a consecutive inhomogeneity in the plume. An additional criterion is thus required to determine a relevant time-lag by selecting the first local maximum of the CCF function. Moreover, this maximum is retained only if it presents a significant amplitude above a given threshold, which needs to be determined. If these criteria are not fulfilled, velocity cannot be estimated. Note that the longer the window, the less likely this artifact will arise, given that secondary peaks are more flattened due to the larger number of points taken into account for the correlation calculation.

A threshold is imposed on the local maximum in the cross correlation function, which has to exceed 0.5 to be retained. Indeed, a threshold of 0.8 removes irrelevant very low velocities of $\sim 0.1 \mathrm{~m} \mathrm{~s}^{-1}$, but also some relevant output speed values. With these additional criteria (considering a threshold of 0.5 ), we mainly observe velocities ranging from $1-2.5 \mathrm{~m} \mathrm{~s}^{-1}$, with values very similar for both narrow and long windows (Fig. 3b). Estimates are not identical. Narrow window speeds are more dispersed because they represent near instantaneous velocities rather than the averaged ones obtained with the long window. Some limits of the correlation analysis using a narrow window, associated with characteristics of the gas plume, remain and explain large discrepancies with the speeds estimated using a long window. They lead to velocities mostly below $0.5 \mathrm{~m} \mathrm{~s}^{-1}$ or higher than $2.5 \mathrm{~m} \mathrm{~s}^{-1}$. These limits in the method are explained in Appendix B. 


\section{Results}

\subsection{Time-series of $\mathrm{SO}_{2}$ column amounts}

$\mathrm{SO}_{2}$ column amount time-series obtained for both spectrometers (Fig. 2) reveal similar patterns, with a time delay expected for the upper instrument dataset corresponding to the time for an inhomogeneity to travel from the first to the second spectrometer FOV. The slight differences in amplitude between the time-series can result from various processes.

The sensitivity of both instruments can be assumed to have a multiplicative effect on the measured light intensity. Optical depths and gas column amounts are consequently independent of it. On the other hand, the error in the column amount from the DOAS retrieval, resulting from the fitting procedure (Stutz and Platt, 1996; Hausmann et al., 1999), is between 3 and $12 \%$ for both instruments. It explains a part of these differences.

Additional errors in the column amount are linked to the scattering of light by air molecules and particles (Millan, 1980; Platt et al., 1997; Mori et al., 2006). The modelling work of Kern et al. (2009) gives a quantification of this effect, including in-plume multiple scattering and the 'light dilution effect'. Given the low $\mathrm{SO}_{2}$ column amounts and aerosol load (with an aerosol extinction coefficient assumed to be less than $0.5 \mathrm{~km}^{-1}$, as at Etna (Fiorani et al., 2009)), the very limited ash content in the Erebus plume, and the distance $(\sim 2 \mathrm{~km})$ between plume and spectrometers, the error on the estimated column amount is less than $10 \%$ over the wavelength range used for retrieval (308-330 nm). Nevertheless, the impact of the light dilution effect may be underestimated with this study which does not consider a wide spectrometer angle of observation, especially when the plume is far from filling 
the whole field of view. More experiments would be required to quantify this phenomenon. Finally, light scattering influences the absolute amount of gas but should have a negligible impact on the differences identified between spectrometers because they are both pointing at about the same altitude, equivalent to just $75 \mathrm{~m}$ apart when projected to the crater, leading to negligible differences in light path lengths.

The plume studied in this experiment was mainly vertical. Contrary to horizontal plumes, which are principally advected by the wind, vertical plumes rise due to buoyancy. They can be influenced by the local wind field at an altitude where their vertical buoyancy-induced velocity is smaller than the horizontal component of the wind. At this stage, they expand laterally forming a bend. If the two fields of view intersect such a bend, gas molecules are effectively "counted" more than once, leading to an over-estimation of the column amount. It can explain differences in column amount time-series, the higher spectrometer being potentially the only one affected. We checked video footage recorded during our experiment and observed occasionally a bend in the plume at a height less than $200 \mathrm{~m}$ above the crater, i.e., below the altitude of the upper spectrometer's FOV. It happened during three time intervals (0-939,1464-1866,3354-3791 s after the start time of 20:24 h GMT), and the column amounts measured with the upper instrument were only $2-$ $10 \%$ higher than those obtained with the lower spectrometer (see Fig. 2). Consequently, this issue only weakly affects the results.

An additional process is associated with the presence of stagnant, diffuse $\mathrm{SO}_{2}$ around the plume, which sometimes forms a thin veil as seen on the video. This background pollution is hard to quantify but is certainly 
negligible compared with the previously mentioned processes.

Errors on column amounts (CA) are less than $10 \%$ for each spectrometer. The main differences between the two CA time-series are of higher magnitude and cannot be due to any of theses artifacts but result from atmospheric phenomena to be discussed later. The lower field of view is likely to present the time variations in column amount the closest to those of the emission of gas at the magma source. It is consequently chosen for the flux estimation.

\subsection{Plume speed time-series}

We have seen in Section 2.3.2 some issues encountered when the plume speed is evaluated with a narrow correlation window (here of $2.5 \mathrm{~min}$ ), due to limits of the correlation analysis method. When evaluations are available, estimated speeds are closer to real-time values, which is of considerable interest when studying very short-term eruptive behaviour such as explosions. There was no Strombolian activity during our experiment, and we are primarily interested in exploring periodic behaviour with cycles around 10 min. For this reason, the $\mathrm{SO}_{2}$ flux is calculated from the speed estimated with a longer correlation window of $10 \mathrm{~min}$ (Fig. 5b). Cross correlation coefficients used for wind speed determination are shown in Fig. 5c with values most of the time significantly higher than the chosen threshold of 0.5 . The average plume velocity varies smoothly over the range $1-2.5 \mathrm{~m} \mathrm{~s}^{-1}$. By a basic differential calculation from Equation 2.2, the uncertainty in the speed is estimated as $0.1 \mathrm{~m} \mathrm{~s}^{-1}$ considering uncertainties in the distance between the two spectrometer's fields of view $\left(\Delta d_{Y}\right)$ and in the time lag between the upper and lower column amount signals $\left(\Delta \tau_{\text {lag }}\right)$ of respectively $9 \mathrm{~m}$ and $2 \mathrm{~s} . \Delta d_{Y}$ is dependent on, respectively, the uncertainties in the angle $\beta$ between the two 
spectrometers' fields of view, taken to be $2 \pm 0.2^{\circ}$ (our goniometric stage has a precision of $0.1^{\circ}$ but the resulting uncertainty is considered greater considering imperfections in the structure supporting both spectrometers); the elevation angle $\alpha$ of the lowermost field of view which is $12 \pm 0.5^{\circ}$; and the horizontal distance $D$ between observation site and plume which is 1960 $\pm 50 \mathrm{~m} . \Delta \tau_{\text {lag }}$ results from the common width of the cross-correlation function maximum, which provides an estimate of the time-lag. It is important to note that the obtained velocity represents an average value of the plume speed between the two spectrometer FOVs. In reality, a deceleration of the plume rise is expected due to a loss of buoyancy with ascent. Moreover, the speed is also averaged over the length of the correlation window, used to estimate the time-lag, as mentioned above.

Plume velocities estimated with the DW-FOV DOAS are similar to speeds evaluated using video techniques. To estimate speed from the video, we tracked clearly defined fronts of ascending puffs (on a time scale of $30 \mathrm{~s}$ ) and used for a distance scale mapped asperities on the crater rim (clearly visible in the video). Decreasing velocities (averaged at $30 \mathrm{~s}$ ) were seen, in the range $2.8-2.1 \pm 0.4 \mathrm{~m} \mathrm{~s}^{-1}$ for altitudes ranging from 165 to $230 \mathrm{~m}$ above the crater, which correspond approximately to the heights of the spectrometers' fields of view at $\sim 78$ and $\sim 150 \mathrm{~m}$ (note that speeds were estimated with video at slightly higher altitudes than spectrometer FOVs, where puff fronts were better defined). The uncertainty in this speed arises from the difficulty in locating precisely the gas puff front (at $\pm 10 \mathrm{~m}$ ), the error on the distance scale seen in the video field of view (estimated at $260 \pm 5 \mathrm{~m}$ ) being negligible 
341

by comparison. It is also in agreement with theoretical estimations of the rise rate of a buoyant gas puff, which are in the range $0.6-3.2 \mathrm{~m} \mathrm{~s}^{-1}$ at Erebus as shown in Appendix C.

\section{3. $\mathrm{SO}_{2}$ flux time-series}

Given that the gas column amount $C A_{W F O V}$ measured with a wide field of view spectrometer approximately represents the average column amount along the different directions in the wide angle of observation (see Section 2.2 and Appendix A), the gas flux (in $\mathrm{kg} \mathrm{s}^{-1}$ ) estimated with this new technique is obtained from:

$$
\phi=\left(C A_{W F O V} \frac{10^{4} M}{N_{A v}} \times \frac{D}{\cos \alpha} \theta_{W F O V}\right) \cdot v,
$$

considering a column amount in molec $\mathrm{cm}^{-2}, M$ the gas molar mass in $\mathrm{kg}$ $\mathrm{mol}^{-1}$ and $N_{A v}$ Avogadro's number. At Erebus, the $\mathrm{SO}_{2}$ flux measured during $\sim 1.7 \mathrm{~h}$ on the 26 December 2006 varies between 0.17 and $0.89 \mathrm{~kg} \mathrm{~s}^{-1}$ (Fig. 5 a). The uncertainty in the flux is estimated at $0.2 \mathrm{~kg} \mathrm{~s}^{-1}(\sim 33 \%$ on the mean flux). This low value represents a considerable improvement in the accuracy of flux measurements. It depends on the different uncertainties, listed by order of magnitude, linked to the elevation angle of the lowermost FOV, the column amount (assumed equal to 10\%), the plume speed, and the wide angle of FOV aperture (assuming an uncertainty on $\theta_{W F O V}$ of $1^{\circ}$ resulting from the adjustment of the lenses mounted on the telescopes) leading each of them to an uncertainty in the range $0.03-0.06 \mathrm{~kg} \mathrm{~s}^{-1}$ on the flux. Note that this obtained flux may include some gas emitted from a secondary vent 
within the crater known as Werner vent, though no lava was present within it during the experiment.

Estimations of the gas flux with the DW-FOV DOAS are similar to previous measurements:

- measurements of $0.86 \pm 0.20 \mathrm{~kg} \mathrm{~s}^{-1}$ carried out in December 2003 by Oppenheimer et al. (2005) by the traverse method beneath a horizontally advected plume travelling at $5.1 \mathrm{~m} \mathrm{~s}^{-1}$ (the plume speed was derived from two DOAS spectrometers aligned along the plume axis).

- the mean flux between 1992 and 2005 of $0.7 \pm 0.3 \mathrm{~kg} \mathrm{~s}^{-1}$, estimated by scanning vertical plumes each field season over two to five days in December, with plume speeds obtained from video methods by Kyle et al. (1994).

The $\mathrm{SO}_{2}$ flux from Erebus is low compared to many volcanoes but is similar to Erta 'Ale in Ethiopia, which also hosts a persistent lava lake (Oppenheimer et al., 2004). An animation showing the results in the form of an " $\mathrm{SO}_{2}$ fluxmeter" superimposed on video of the plume, is available as an electronic supplement to this article.

\subsubsection{Time-series analysis of flux data for Erebus}

In view of the likely non-stationarity of $\mathrm{SO}_{2}$ output from Erebus, we use wavelet analysis to explore any frequencies present in the signal, as well as their variability with time. Analysis of the flux time-series is achieved here using a continuous transform with a complex Morlet wavelet (Fig. 6). This wavelet analysis is particularly suitable to study our non-stationary time-series, where smooth variations in the frequency content are expected. 
Moreover, the Fourier transform of a complex Morlet wavelet presents an analytical expression, simplifying calculations of the wavelet transform. Full details concerning the method of analysis are given in Appendix D. Concerning our time-series, high-frequencies are associated with variations of smaller amplitude of the signal than lower frequencies, and are consequently less energetic and visible in the wavelet analysis. We broadly distinguish three populations of distinctive periods, associated to approximately the same power at both spectrometers, which can be listed by decreasing energy as follows:

- Pattern 1: periods in the range 700-1300 s ( 11-22 min) for upper spectrometer; and in the range 800-1400 (possibly more) s ( 13-24 min) for lower spectrometer, which are energetic during the whole dataset.

- Pattern 2: periods in the range 300-600 s ( 5-10 min) for upper spectrometer, energetic until $\sim 3200 \mathrm{~s}$; periods in the range 400-600 s ( $\sim 6.5-$ $10 \mathrm{~min}$ ) for lower spectrometer, less energetic than at the upper instrument, present until $\sim 2000$ s.

- Pattern 3: periods in the range 100-200 s ( 1.5-2.5 min) for both spectrometers, appearing irregularly during the experiment.

Calculating the wavelet transform of both flux signals, to which a white noise of a chosen amplitude (equal to $0.1 \mathrm{~kg} \mathrm{~s}^{-1}$ here) has been added, allows us to test the significance of the results. The resulting wavelet analysis is slightly different but still shows peaks in power associated with the groups of periods mentioned above, including the less energetic Pattern 3 which is consequently well above the noise level and consistent. In addition, wavelet analysis was also performed on portions of the data set without gaps (i.e. 
before $2000 \mathrm{~s}$ ), verifying that these gaps, where linear interpolation was performed, do not influence the results.

\section{Discussion}

\subsection{Methodology}

The basis of the DW-FOV DOAS system to record high-temporal resolution flux measurements relies on the estimation of the plume velocity by following inhomogeneities between the two spectrometers' fields of view crossing the plume. It is consequently important to orientate fields of view closely to the perpendicular direction to plume transport in order not to gather dissimilar plume parts in a FOV. The distance between both FOVs has also to be carefully chosen in order to allow a relevant correlation analysis. It must not be too large such that structures recorded by the lower instrument are substantially modified or lost by the time they reach the upper spectrometer. The half-life of a turbulent inhomogeneity can be estimated considering the auto-correlation function of the column amount time-series where it corresponds to the width of its first peak ( $\sim 70 \mathrm{~s}$ at Erebus). A large distance can also average out variations in plume speed, especially for vertical plumes which typically decelerate. Fields of view that are too close can also impede identification of elongated puffs, which cannot be adequately differentiated during their rise from the lower to the upper field of view to carry out a meaningful correlation. Depending on the plume velocity, the minimum distance of separation is also dictated by the data sampling frequency, as well as by the uncertainty of the method of correlation analysis. Furthermore, the travel time of one inhomogeneity to reach the second field of view must be 
less than any periodicity of the volcanic degassing to avoid irrelevant results of the correlation analysis. As a consequence, the optimum distance between the two fields of view inside the plume will vary from one volcano to another, depending also on its activity.

Reducing the main sources of uncertainty in the gas flux estimations will improve the method. In particular, a more accurate estimation of the elevation angle of the spectrometer FOVs could be achieved quite straightforwardly. Concerning the instrument, lenses mounted on the two telescopes gave a fixed horizontal field of view width adjusted for the typical width of the Erebus plume. We have since constructed a telescopic system with adjustable fields of view to adapt to different situations. This could be particularly useful for a horizontal plume, which can display more variable dimensions with time depending on the local wind field. Vigilance is indeed required to make sure that the whole plume is captured in the wide angle of observation.

\subsection{Interpretation of degassing patterns}

Wavelet analysis of the flux time-series identifies three patterns in Erebus degassing (see Fig. 6 and Section 3.3.1). The most noticeable one, in terms of energy, includes periods in the range 11-24 min which are manifest during the whole data set and for both spectrometers. The second pattern is associated with 5-10 min cycles, but is only apparent during the first half of the experiment. It is relevant to note that this behaviour is more pronounced, and that the signal is stronger, in data from the upper spectrometer (see Fig. 6 ). This suggests that the signal results from the large scale organization of turbulence inside the plume developing with height above the crater. This is 
commonly observed at chimneys expelling a constant gas flux where structure develops with altitude. Thus, this part of the signal yields no information about the magma source but rather the atmospheric processes modifying the large gas puffs associated with the first pattern of degassing. Further investigation would be required to quantify this influence and its dependence on the distance between the magmatic source and the plume sections crossed by the spectrometers' fields of view. The third pattern in degassing consists of short period fluctuations of the flux in the range 1.5-3 min, which appear several times during the experiment. They reveal the exhalations of smaller gas puffs covering just one part of the crater, as illustrated in the video (see electronic supplement). In the next section, we explore the magmatic processes that can explain the $\mathrm{SO}_{2}$ flux variability focusing on Pattern 1, associated with cycles with 11-24 min period. Note that no explosions occurred during our observations according to seismic and acoustic observations.

\subsubsection{Periodic gas-rich magma supply to the lava lake}

Periodic $\mathrm{SO}_{2}$ degassing could be linked to pulsatory discharge of gas-rich magma into the lava lake. Such magma flow could result from different processes. Magma convection in the conduit can promote the persistence of long-lived lava lakes with sustained degassing (Francis et al., 1993; Kazahaya and Shinohara, 1994; Stevenson and Blake, 1998). The models assume bi-directional flow of a less dense, lower viscosity ascending magma, and a degassed, denser and more viscous descending magma. It has been shown that Erebus lava lake has a sufficiently large feeder conduit radius to maintain this process for assumed viscosity and density contrasts between rising and sinking magma (Calkins et al., 2008). Oppenheimer et al. (2009b) argued 
that the viscosity stratification induced by such bi-directional magma flow can lead to boudinage of the rising gas-rich magma and explain a pulsatory supply of magma into the lake (Fig. 7a).

Variations in magma viscosity can also lead to periodic magma flow. Wylie et al. (1999) have modelled magma rise dynamics assuming a constant flux at the base of an elastic conduit. They showed how the dependence of viscosity on volatile content can lead to an oscillating magma flow at shallow depth, given a relevant range of model input parameters (Fig. 7b). This model was applied to the andesitic Soufriere Hills Volcano (Montserrat), indicating an unstable magma flow with oscillation periods of a few hours, but it should be valid more generally during closed system degassing. However, no analytical expression is given for the oscillation frequency. Thus we cannot identify if it reproduces the 11-24 min periodic degassing observed at Erebus, but it does provide a plausible conceptual mechanism. Periodic magma flow could also result from pressurization feedbacks between magma ascent rate, crystallization, and open vs. closed-system degassing, which have been proposed as an explanation for the periodic behaviour of andesitic and silicic domes (Melnik and Sparks, 1999; Barmin et al., 2002).

A further explanation for periodic magma ascent is stick-slip movement along the conduit walls (Denlinger and Hoblitt, 1999). This mechanism can be ruled out for Erebus given the absence of corresponding seismicity - the few long period earthquakes that are recorded there are associated with Strombolian explosions (Aster et al., 2003, 2008). 


\subsubsection{Periodic gas supply to the lava lake}

Gas segregation at the roof of a magma reservoir (Jaupart and Vergniolle, 1989) or in asperities such as horizontal intrusions leading from a magma conduit (Menand and Phillips, 2006), has been suggested to explain intermittent Strombolian explosions. This mechanism considers the progressive accumulation of a gas foam that grows and becomes unstable above a critical thickness. The foam then collapses as bubbles coalesce, resulting in expulsion of overpressured gas slugs that rise to the surface generating explosions. Since there were no explosions at Erebus during the period of our experiment, we consider a variation of this process that might result in periodic passive degassing. Rather than an asperity with sharp boundaries, we consider a continuous, smooth cavity in the conduit walls, as illustrated in Fig. 7c. The gas expelled to the atmosphere is then a mixture of two sources: one, a continuous degassing from a magma rising directly from depth to surface; the other associated with the accumulation of gas in a smooth conduit cavity, which depends on the size of this segregator as well as the rising gas and magma fluxes. This smooth geometry does not allow the collapse of a gas foam but rather the regular retention and extraction of the accumulating foam. This would permit a continuous passive release of gas from the lava lake with a periodic pattern depending on the rate of gas accumulation at some depth in the magmatic system.

\subsubsection{Complementary geochemical and geophysical observations}

These two groups of physical processes allow us to interpret not only the observed periodic flux of $\mathrm{SO}_{2}$ but also diverse geochemical and geophysical measurements made during other field seasons at Erebus. Unfortunately, 
when our DW-FOV DOAS spectra were recorded in December 2006, it was already late in the field season and other instruments (thermal camera and FTIR spectrometer) were not running; so we cannot explore the correlation between the time varying behaviour of gas flux with other parameters. Nevertheless, it is of particular interest to note that a similar periodicity of about 10 min has been identified in December 2004 from analysis of both thermal imagery of the lava lake and gas composition measured by Fourier transform infrared spectroscopy (Oppenheimer et al., 2009b). These observations revealed cycles in lava lake convection (surface speed and direction) and heat output with periods of 4-15 min, that were phase-locked with cyclic changes in gas composition $\left(\mathrm{SO}_{2} / \mathrm{CO}_{2}\right.$ and $\mathrm{HCl} / \mathrm{CO}$ ratios). Column amounts of gases measured between the crater rim and the lake surface (a distance of about $300 \mathrm{~m}$ ) also revealed the same cyclicity, suggesting that gas fluxes were very likely periodic too. Both types of model discussed above can account for these additional observations but only gas segregation offers an explanation for the seismicity at Erebus and complementary geochemical measurements. The stability of oscillatory, very long period signals preceding Strombolian eruptions, over a span of five years, suggests a stable near-summit reservoir with multiple sites for gas slug coalescence as VLP sources (Aster et al., 2003, 2008). Shallow magma sequestration is also proposed to interpret measurements of water and carbon dioxide fluxes from Erebus, which reveal that not all the magma that supplies the $\mathrm{CO}_{2}$ emitted from the lake can reach the surface, since otherwise the $\mathrm{H}_{2} \mathrm{O}$ flux should be much higher than observed (Oppenheimer and Kyle, 2008). Note that the presence of a $\mathrm{CO}_{2}$ rich preexisting fluid phase, not trapped in melt inclusions, could also explain this 
observation.

\subsection{Further remarks}

This study shows the value of accurate high resolution flux data to explore variability in magma degassing. Our experiment was only of short-duration and we only had simultaneous video images as additional data. This precludes discrimination between the alternative models for the periodic degassing behaviour of Erebus that we identified. However, it paves the way for further investigation, which will greatly benefit from complementary volcanological observations including thermal imagery, and FTIR spectroscopy to constrain the depths of gas sources in the magmatic network, the mechanisms of gas segregation, and the different modes of gas transport. A better knowledge of the magma plumbing system with the dimension of potential gas storage regions could be explored further through seismic studies. Eventually, developing physical models from conceptual mechanisms will help to determine the range of input parameters (including in particular rising gas and magma fluxes, magma rheology, the dimension of gas bubbles, and the geometry and size of gas segregators) that would lead to periodic degassing, and how the expected periodicity at Erebus could be modelled analytically.

\section{Conclusions}

We have described the construction of a dual wide field of view UV spectroscopic system designed for the high temporal resolution measurement of volcanic gas fluxes (principally of the species $\mathrm{SO}_{2}$ ). The novelty of the instrumental set up lies in the use of a combination of spherical and cylindrical 
lenses, which present an elongated field of view that is oriented perpendicularly to the plume transport direction so as to observe all $\mathrm{SO}_{2}$ molecules present simultaneously (without the need for imaging, motion or scanning). Additionally, the two fields of view are separated by a small angle that permits tracking of plume inhomogeneities in the time-stamped datasets obtained from each spectrometer. The data analysis includes DOAS retrieval of gas column amounts and correlation analysis of the time-varying signals recorded at the two spectrometers, whose angular separation indicates the separation distance between the two instrument fields of view projected to the plume. The deployment of the system is relatively simple and it can be used, in principle, on any plume rising vertically or drifting horizontally, where the basic plume and viewing geometry can be measured with some certainty. Processing of the data could also be achieved in real-time, and it would only require limited further development to yield a real-time flux meter, capable of measurements at a frequency of $1 \mathrm{~Hz}$ or better, with accuracy of $33 \%$ or better.

This method allows the study of short-term variations in volcanic degassing. We have demonstrated the vigilance required to discriminate between fluctuations linked to atmospheric processes from those resulting from magmatic activity. At Erebus, a particularly noticeable periodicity in the range 11-24 min is apparent in the $\mathrm{SO}_{2}$ degassing rate. Two groups of physical processes can explain this oscillatory behaviour. The first involves a periodic supply of gas-rich magma to the lava lake, which may result either from boudinage of the rising magma flow due to shear stresses between ascending and descending magmas in a bi-directional conduit flow, or from a 
612

volatile-dependent viscosity leading to an oscillating magma flow. The second mechanism is associated with periodic supply of gas to the lake arising from gas segregation in smooth cavities in the conduit. Smaller gas puffs, leading to short-period fluctuations of the flux lasting a few minutes, are also observed intermittently. A longer experiment duration, combining flux measurements with other volcanological data streams, is needed to discriminate between the suggested source mechanisms for this particular degassing behavior. This would improve understanding of gas and magma dynamics and storage in the Erebus plumbing system.

\section{A. Meaning of the column amount measured with DW-FOV DOAS spectrometers}

The elemental light power $d \Phi$ received from the solid angle $d \Omega$, associated to longitude $\theta$ and latitude $\alpha$, by a lens aperture of surface $A_{r}$ is a function of the radiance (or intensity) $L$ :

$$
d \Phi=A_{r} L(\theta, \alpha) d \Omega
$$

Considering a small lens aperture surface, the total light power received by a wide field of view capturing instantaneously the whole horizontal plume cross-section spectrometer is given by:

$$
\Phi=A_{r} \int_{-\theta_{N F O V} / 2}^{+\theta_{N F O V} / 2} \int_{-\theta_{W F O V} / 2}^{+\theta_{W F O V} / 2} L(\theta, \alpha) d \Omega
$$


625

627

631

630

where $\theta_{W F O V}$ and $\theta_{N F O V}$ are, respectively, the wide horizontal and narrow vertical angles of aperture of the field of view. The elemental solid angle can be written in spherical coordinates:

$$
d \Omega=\cos \alpha d \theta d \alpha
$$

The vertical angle of aperture of the wide field of view spectrometers $\theta_{N F O V}$ being very small $(8 \mathrm{mrad})$, the radiance can be assumed constant on the range of considered latitudes $\alpha$. The total light power (Eq. A.2) is thus given by:

$$
\Phi=A_{r} \theta_{N F O V} \int_{-\theta_{w f o v} / 2}^{+\theta_{w f o v} / 2} L(\theta) d \theta
$$

and can be rewritten:

$$
\Phi=A_{r} \theta_{N F O V} \theta_{W F O V} \bar{L}(\theta)
$$

with $\bar{L}$ the mean radiance for $\theta \in\left[-\theta_{W F O V} / 2 ; \theta_{W F O V} / 2\right]$. An equivalent equation is valid for the light power received from the background sky

$$
\Phi_{b g}=A_{r} \theta_{N F O V} \theta_{W F O V} \bar{L}_{b g}(\theta)
$$
Combining Eq. A.5 and A.6, we have: 


$$
\frac{\Phi}{\Phi_{B g}}=\frac{\bar{L}}{\overline{L_{b g}}} .
$$

632

646

647

Moreover, according to the Beer-Lambert law (simplified here by not explicitly including low-frequency components), we have:

$$
L(\theta)=L_{b g}(\theta) e^{-\sigma C A(\theta)},
$$

where $\sigma$ is the cross-section of the considered gas species and $C A(\theta)$ its slant column amount in the direction defined by $\theta$. Note that the proof is exactly the same with the complete Beer-Lambert law, merely an additional step is required to remove the low-frequency component. We would obtain in this case the above equation, where $\sigma$ would just be replaced by its associated differential cross section. A limited development of the exponential is valid for Eq. A.8 if we have weak optical depths (i.e. $\sigma C A(\theta)<<1$ ). This is the case at Erebus considering the emission of sulfur dioxide, where this product is close to $10^{-2}$, with a $\mathrm{SO}_{2}$ slant column amount of the order of $10^{17}$ molec $\mathrm{cm}^{-2}$ and $\sigma_{\mathrm{SO}_{2}} \sim 10^{-19} \mathrm{~cm}^{2}$. It follows that:

$$
L(\theta) \sim L_{b g}(\theta)(1-\sigma C A(\theta))
$$

646

48

9
If we take the mean of this expression with $\theta$, assuming that the background has been collected for a uniform or clear sky and that $L_{b g}$ is consequently negligibly dependent on $\theta$, we find: 


$$
\bar{L} \sim L_{b g}(1-\sigma \overline{C A}) .
$$

650

652

654

655

656

Therefore, Eq. A.7 can be rewritten:

$$
\frac{\Phi}{\Phi_{B g}} \sim(1-\sigma \overline{C A})
$$

Given again $(\sigma \overline{C A}<<1)$, Eq. A.11 is approximated by:

$$
\Phi \sim \Phi_{b g} e^{-\sigma \overline{C A}}
$$

with

$$
\overline{C A}=\frac{1}{\theta_{W F O V}} \int_{-\theta_{W F O V} / 2}^{+\theta_{W F O V} / 2} C A(\theta) d \theta .
$$

Consequently, the column amount measured with the wide field of view spectrometer $C A_{W F O V}$ represents the mean column amount along the different directions $\theta$ inside the wide angle of observation $\theta_{W F O V}$. This result has been proved assuming weak optical depths here. But it is generally valid, for any optical depth. In this case, we cannot give an analytical expression for the relationship between $C A_{W F O V}$ and $\overline{C A}$. But we can estimate the error made when assuming the equality $C A_{W F O V}=\overline{C A}$, that will be used then for gas flux estimation with this technique. According to Eq. A.7 and the simplified Beer Bouguer Lambert law Eq. A.8, we have: 


$$
e^{-\sigma C A_{W F O V}}=\overline{e^{-\sigma C A(\theta)}} .
$$

666

$$
e^{-\sigma C A_{W F O V}}=1-\sigma C A_{W F O V}+\int_{0}^{\sigma C A_{W F O V}}\left(\sigma C A_{W F O V}-t\right) e^{-t} d t
$$

667

and

$$
\overline{e^{-\sigma C A(\theta)}}=1-\sigma \overline{C A(\theta)}+\overline{\int_{0}^{\sigma C A(\theta)}(\sigma C A(\theta)-t) e^{-t} d t .}
$$

668 669

As a consequence, writing Eq. A.14 from Eq. A.15 and A.16 gives the error made by approximating $C A_{W F O V}$ by $\overline{C A}$ :

$C A_{W F O V}-\overline{C A(\theta)}=\frac{1}{\sigma}\left(\int_{0}^{\sigma C A_{W F O V}}\left(\sigma C A_{W F O V}-t\right) e^{-t} d t-\overline{\int_{0}^{\sigma C A(\theta)}(\sigma C A(\theta)-t) e^{-t} d t}\right)$,

which gives after majoration

$$
\left|\frac{C A_{W F O V}-\overline{C A(\theta)}}{\overline{C A(\theta)}}\right| \leq \max _{\theta}(C A) .
$$

Fig. 8 illustrates the evolution of this relative error according to the strength of gas emission from the studied volcano.

\section{B. Cases of failure of the correlation analysis linked to plume char- acteristics \\ Correlation analysis is successful when clearly defined structures are present in the selected window. But failures show up in the following cases:}


- when a structure in the degassing is recorded at the first spectrometer but has faded or completely dissipated by the time it reaches the second spectrometer.

- when there is no structure in the plume. In this case, the maximum of the $C C F$ function which is obtained is not meaningful due to the presence of a few peaks with similar amplitudes. Checking the video footage recorded simultaneously with the DOAS measurements, we observed that these limits in the correlation analysis do occur when the plume appears less distinct with elongated and very few structured puffs, as opposed to smaller puffs with a clearly defined rise front due to a large contrast of density with the surrounding air.

\section{Theoretical estimation of a rise speed of a buoyant puff}

According to seismic observations, there were no explosions during our period of spectroscopic measurements and degassing consisted of the passive release of magmatic gases from the lava lake. The rise of these hot gas puffs, or thermals, is consequently mainly driven by buoyancy and not by an initial source momentum. Their ascent, during which they rapidly entrain colder atmospheric air through a large organized vortex ring and expand, can be described by fluid dynamics. If a fully turbulent regime is assumed, an analytical solution of the three coupled equations of mass, momentum and energy conservation is possible. It is self-similar with distance from the source $z$ and for a non density stratified atmosphere can be written as (Morton et al., 1955; Turner, 1979; Sparks et al., 1997; Branan et al., 2008): 


$$
\begin{array}{r}
r=\epsilon z \\
v=\left(\frac{B_{0} r_{0}^{3}}{3 \epsilon^{3}}\right)^{1 / 2} \frac{1}{z} \\
B=\frac{B_{0} r_{0}^{3}}{\epsilon^{3}} \frac{1}{z^{3}}
\end{array}
$$

with the expression of the buoyancy

$$
B=g\left(\frac{\rho_{a}-\rho_{p}}{\rho_{a 0}}\right),
$$

where $r$ is the radius of the puff which is assumed spherical, $v$ its vertical velocity, $\epsilon$ the entrainment constant (with an empirically determined value of 0.25 for fully turbulent laboratory thermals (Scorer, 1957; Turner, 1979)), $g$ the acceleration due to gravity, $\rho_{p}$ and $\rho_{a}$ the bulk density of, respectively, the puff and the surrounding atmospheric air. The subscript 0 refers to the variable value at the source of the puff release, which is the lava lake at Erebus.

Note that an idealized point source is an unrealistic initial condition. This flow description is consequently not valid very close to the source. We show that it can been applied at the altitude of the DOAS measurements, just above the crater rim $(\sim 220 \mathrm{~m}$ above the lake). Indeed, this model predicts spherical puffs with a radius of $55 \mathrm{~m}$, which is consistent with estimates made from available photographs and video where it varies between 45 and $68 \mathrm{~m}$. According to Eq. C.2, the puff vertical speed mainly depends on the source 
radius $r_{0}$ via an exponent of 3 , and at second order on the reduced gravity $B_{0}$.

An upper value for the source size is the dimension of the lava lake whose the radius is $\sim 17.5 \mathrm{~m}$. A better constrained range of estimates can also be deduced from the dilution coefficient $d$, defined as the ratio of the initial puff volume to the volume at the measurement height, which can be written:

$$
d=\left(\frac{r_{0}}{r}\right)^{3}
$$

From Fourier Transform Infrared (FTIR) spectroscopy carried out from the crater rim along the $300 \mathrm{~m}$ path to the lava lake, a mean mixing ratio of $\sim 0.001$ is evaluated and gives a rough indication of the dilution coefficient which can be assumed to range in 0.01-0.001. According to photographs, for a puff radius at the measurement altitude of 44-68 m, Eq. C.5 gives a source radius in the range $4.5-14.5 \mathrm{~m}$.

The puff consists of a gas mixture $\left(10 \mathrm{~kg} \mathrm{~s}^{-1}\right.$ of water; $15 \mathrm{~kg} \mathrm{~s}^{-1}$ of $\mathrm{CO}_{2}$, total gas flux of $27 \mathrm{~kg} \mathrm{~s}^{-1}$ ) (Oppenheimer and Kyle, 2008), whose density follows the perfect gas law. Its value at the source is $\sim 0.2 \mathrm{~kg} \mathrm{~m}^{-3}$ for an initial puff temperature of $1273 \mathrm{~K}$, an atmospheric air temperature of $250 \mathrm{~K}$ and pressure of $\sim 0.6310^{5} \mathrm{~Pa}$ for Erebus summit altitude $(3798 \mathrm{~m}$ above sea level). From Eq. C.2, assuming an atmospheric bulk density of $0.88 \mathrm{~kg} \mathrm{~m}^{-3}$, the puff vertical velocity is in the range $0.6-3.2 \mathrm{~m} \mathrm{~s}^{-1}$.

Note that the assumption of a turbulent regime can be checked afterwards. The Reynolds number associated with the puff rise dynamics has the expression: 


$$
R e_{P}=\frac{v z \rho_{P}}{\mu_{P}},
$$

740

755

where $\mu_{P}$ represents the gas puff dynamic viscosity (of $\sim 5 \times 10^{-6} \mathrm{~Pa} \mathrm{~s}$ according to Sutherland's formula describing viscosity variations with temperature, though this calculation is made outside the calibration range for a temperature of $555 \mathrm{~K}$ and thus represents an approximation). For a mean vertical speed of $2 \mathrm{~m} \mathrm{~s}^{-1}, \operatorname{Re}_{P}$ is $\sim 10^{7}$ at the measurement height, i.e. much greater than $10^{4}$ and demonstrating a fully turbulent flow.

This description of the plume rise does not consider the potential convective flux of air that is heated by the surface of the lava lake. It can reduce the contrast of temperature between the puff and the surrounding air, slowing the puff rise. On the other hand, it can also entrain the puff and accelerate its ascent. This effect has counterbalancing consequences and is neglected.

\section{Wavelet analysis}

A time-series analysis is performed using a complex Morlet wavelet with the expression

$$
\Psi(t)=\frac{1}{\pi^{1 / 4}}\left(e^{+i \omega_{0} t}-e^{-i \omega_{0}^{2} / 2}\right) e^{-t^{2} / 2}
$$

55

56

$\omega_{0}$ is taken equal to $2 \pi$ and is consequently superior to 5 in order to satisfy the wavelet admissibility condition (Farge, 1992). The second term of Eq. D.1 is also thus negligible and the Fourier transform of this wavelet is simply a Gaussian function, which facilitates the calculation of the wavelet 
transform (Torrence and Compo, 1998). We chose to express the wavelet analysis as a function of a set of scales $a$ linearly distributed between $T_{\min }$ and $T_{\max }$, which represent the shortest and longest time periods that we can study. They are, respectively, taken as equal to twice the time spacing of the dataset (1 $\mathrm{s}$ here) and less than half the duration of the entire data set ( $\sim 4000$ s), in order to satisfy the Nyquist-Shannon sampling theorem. Note that the scales associated with a Morlet wavelet are almost equal to Fourier periods for $\omega_{0} \sim 6$ (Torrence and Compo, 1998). This analysis is carried out on flux time-series that are linearly interpolated to fill the few data gaps in plume speed estimations resulting from the lack of plume structure, assuming continuous variations of the velocity. The domain where the wavelet analysis does not suffer from edge effects is delimited by a cone of influence. It is associated with a characteristic time equal to $\sqrt{2} a$, which corresponds to the time where the wavelet power associated to a discontinuity at the edge drops by a factor $e^{-2}$, which ensures that the edge effect is negligible (Torrence and Compo, 1998).

\section{Acknowledgments}

We gratefully acknowledge support from NSF Office of Polar Programs grants (OPP-0229305; ANT-0538414) and the United States Antarctic Program. CO also thanks the Leverhulme Trust for a Study Abroad Fellowship and the EU Framework 6 programme, which supported the project NOVAC. MB thanks the European Commission for an Intra-European Marie-Curie Fellowship (Project VolcanGas 14018), and Olivier De Viron for fruitful discussions concerning signal analysis. CO and PK warmly acknowledge their 
companions in Science Event G-081 and the helicopter pilots, and staff based at McMurdo Station. They particularly thank Dr. Tom Wagner (then NSF Program Manager for Antarctic Geology and Geophysics) for support.

\section{References}

Aster, R., Mah, S., Kyle, P., McIntosh, W., Dunbar, N., Johnson, J., Ruiz, M., McNamara, S., 2003. Very long period oscillations of Mount Erebus Volcano. J. Geophys. Res. 108 (B11, 2552).

Aster, R., Zandomeneghi, D., Mah, S., McNamara, S., Henderson, D., Knox, H., Jones, K., 2008. Moment tensor inversion of very long period seismic signals from Strombolian eruptions of Erebus Volcano. J. Volcanol. Geotherm. Res. 177, 635-647.

Barmin, A., Melnik, O., Sparks, R., 2002. Periodic behavior in lava dome eruptions. Earth Planet. Sci. Lett. 199, 173-184.

Bluth, G., Shannon, J., Watson, I., Prata, A., Realmuto, V., 2007. Development of an ultra-violet digital camera for volcanic $\mathrm{SO}_{2}$ imaging. J. Volcanol. Geotherm. Res. 161, 47-56.

Bobrowski, N., Honninger, G., Lohberger, F., Platt, U., 2006. IDOAS: a new monitoring technique to study the $2 \mathrm{D}$ distribution of volcanic gas emissions. J. Volcanol. Geotherm. Res. 150, 47-56.

Bogumil, K., Orphal, J., Homann, T., Voigt, S., Spietz, P., Fleischmann, O., Vogel, A., Hartmann, M., Kromminga, H., Bovensmann, H., Frerick, J., Burrows, J., 2003. Measurements of molecular absorption spectra with the 
SCIAMACHY pre-flight model: instrument characterization and reference data for atmospheric remote-sensing in the $230-2380 \mathrm{~nm}$ region. Journal of Photochemistry and Photobiology A: Chemistry 157, 167-184.

Branan, Y., Harris, A., Watson, M., Phillips, J., Horton, K., Williams-Jones, G., Garbeil, H., 2008. Investigation of at-vent dynamics and dilution using thermal infrared radiometers at Masaya volcano, Nicaragua. J. Volcanol. Geotherm. Res. 169, 34-47.

Burrows, J., Richter, A., Dehn, A., Deters, B., Himmelmann, S., Voight, S., Orphal, J., 1999. Atmospheric remote-sensing reference data from GOME. 2- Temperature-dependent absorption cross sections of $\mathrm{O}_{3}$ in the 231-794 nm range. J. Quant. Spectrosc. Radiat. Transfer 61 (4), 509-517.

Burton, M., Allard, P., Mur, F., La Spina, A., 2007. Magmatic gas composition reveals the source depth of slug-driven Strombolian explosive activity. Science 317, 227-230.

Calkins, J., Oppenheimer, C., Kyle, P., 2008. Ground-based thermal imaging of lava lakes at Erebus volcano, Antarctica. J. Volcanol. Geotherm. Res.

Denlinger, R., Hoblitt, R., 1999. Cyclic eruptive behavior of silicic volcanoes. Geology 5, 459-462.

Edmonds, M., Herd, R., Galle, B., Oppenheimer, C., 2003. Automated, high time-resolution measurements of $\mathrm{SO}_{2}$ flux at Soufrire Hills Volcano, Montserrat. Bull. Volcanol. 65, 578-586.

Farge, M., 1992. Wavelet transforms and their applications to turbulence. Annu. Rev. Fluid Mech. 24, 395-457. 
Fiorani, L., Colao, F., Palucci, A., 2009. Measurement of Mount Etna plume by $\mathrm{CO}_{2}$-laser-based lidar. Optics Letters 34 (6), 800-802.

Fischer, T., Morrissey, M., V., M. L. C., M., D. G., C., R. T., Stix, J., Williams, S., 1994. Correlations between SO2 flux and long-period seismicity at Galeras Volcano. Nature 368, 135-137.

Fischer, T., Roggensack, K., Kyle, P., 2002. Open and almost shut case for explosive eruptions: vent processes determined by $\mathrm{SO}_{2}$ emission rates at Karymsky volcano, Kamchatka. Geology 30 (12), 1059-1062.

Francis, P., Oppenheimer, C., Stevenson, D., 1993. Endogenous growth of persistently active volcanoes. Nature 366, 554-557.

Galle, B., Oppenheimer, C., Geyer, A., McGonigle, A., Edmonds, M., Horrocks, L., 2003. A miniaturised ultraviolet spectrometer for remote sensing of $\mathrm{SO}_{2}$ fluxes: a new tool for volcano surveillance. J. Volcanol. Geoth. Res. $119,241-254$.

Harris, A., Carniel, R., Jones, J., 2005. Identification of variable convective regimes of Erta 'Ale Lava Lake. J. Volcanol. Geotherm. Res. 142, 207-223.

Hausmann, M., Brandenburger, U., Brauers, T., Dorn, H., 1999. Simple monte carlo methods to estimate the spectra evaluation error in differential-optical-absorption spectroscopy. Applied Optics 38 (3), 462475.

Jaupart, C., Vergniolle, S., 1989. The generation and collapse of a foam layer at the roof of a basaltic magma chamber. J. Fluid Mech. 203, 347-380. 
Johansson, M., Galle, B., Zhang, Y., Rivera, C., Chen, D., Wyser, K., 2009. The dual-beam mini-DOAS technique, measurements of volcanic gas emission, plume height and plume speed with a single instrument. Bull. Volcanol. in press.

Kazahaya, K., Shinohara, H., 1994. Excessive degassing of Izu-Oshima volcano: magma convection in a conduit. Bull. Volcanol 56, 207-216.

Kern, C., Deutschmann, T., Vogel, L., Wohrbach, M., Wagner, T., Platt, U., 2009. Radiative transfer corrections for accurate spectroscopic measurements of volcanic gas emissions. Bull. Volcanol., 1241-1253.

Kyle, P., Sybeldon, L., McIntosh, W., Meeker, K., Symonds, R., 1994. Sulfur dioxide emission rates from Mount Erebus, Antarctica. In: Kyle, P.R. (Ed.), Volcanological and Environmental Studies of Mount Erebus, Antarctica. Vol. 213. American Geoophysical Union, Washington, D.C., pp. $69-$ 82.

McGonigle, A., Hilton, D., Fischer, T., Oppenheimer, C., 2005a. Plume velocity determination for volcanic $\mathrm{SO}_{2}$ flux measurements. Geophys. Res. Lett. 32.

McGonigle, A., Inguaggiato, S., Aiuppa, A., Hayes, A., Oppenheimer, C., 2005b. Accurate measurement of volcanic $\mathrm{SO}_{2}$ flux: determination of plum transport speed and integrated $\mathrm{SO}_{2}$ concentration with a single device. Geochem. Geophys. Geosyst. 6 (Q02003).

McGonigle, A., Oppenheimer, C., 2003. Optical sensing of volcanic gas and aerosol emissions. In: Oppenheimer, C. and Pyle, D.M. and Barclay J. 
(Ed.), Volcanic Degassing. Vol. 213. Geological Society, London, Special Publications, pp. 149-168.

Melnik, O., Sparks, R., 1999. Non linear dynamics of lava dome extrusion. Nature 402, 37-41.

Menand, T., Phillips, J., 2006. Gas segregation in dykes and sills. J. Volcanol. Geotherm. Res.

Millan, M., 1980. Remote sensing of air pollutants, a study of some atmospheric scattering effects. Atm. Environ. 14 (11), 1241-1253.

Moffat, A., Millan, M., 1971. The applications of optical correlation techniques to the remote sensing of $\mathrm{SO}_{2}$ plumes using sky light. Atm. Environ. 5, 677-690.

Mori, T., Burton, M., 2006. The $\mathrm{SO}_{2}$ camera: a simple, fast and cheap method for ground-based imaging of $\mathrm{SO}_{2}$ in volcanic plumes. Geophys. Res. Lett. 33 (L24804).

Mori, T., Mori, T., Kazahaya, K., Ohwada, M., Hirabayashi, J., Yoshikawa, S., 2006. Effect of UV scattering on $\mathrm{SO}_{2}$ emission rate measurements. Geophys. Res. Let. 33 (L17315).

Morton, B., Taylor, G., Turner, J., 1955. Turbulent gravitational convection from maintained and instantaneous sources. Proc. R. Soc. Lond. 234, 1-23.

Oppenheimer, C., 2003. Volcanic degassing. In: Holland, H., Turekian, K. (Eds.), The crust, treatise on geochemistry. Vol. 3. Elsevier-Pergamon, Oxford, Ch. 3.04, pp. 123-166. 
Oppenheimer, C., Bani, P., Calkins, J., Burton, M., Sawyer, G., 2006. Rapid FTIR sensing of volcanic gases released by Strombolian explosions at Yasur volcano, Vanuatu. Applied Physics B. 85, 453-460.

Oppenheimer, C., Kyle, P., 2008. Probing the magma plumbing of Erebus volcano, Antarctica, by open-path FTIR spectroscopy of gas emissions. J. Volcanol. Geotherm. Res. 177, 743-754.

Oppenheimer, C., Kyle, P., Eisele, F., Crawford, J., Huey, G., Tanner, D., Brady, K., Mauldin, L., Blake, D., Beyersdorf, A., Buhr, M., Davis, D., 2009a. Atmospheric chemistry of an Antarctic volcanic plume. J. Geophys. Res. Atm.,--.

Oppenheimer, C., Kyle, P., Tsanev, V., McGonigle, A., Mather, T., Sweeney, D., 2005. Mt. Erebus, the largest point source of $\mathrm{NO}_{2}$ in Antarctica. Atm. Environ. 39, 6000-6006.

Oppenheimer, C., Lomakina, A., Kyle, P., Kingsbury, N., Boichu, M., 2009b. Pulsatory magma supply to Erebus lava lake, Antarctica. Earth Planet. Sci. Lett. 284, 392-398.

Oppenheimer, C., McGonigle, A., Allard, P., Wooster, M., Tsanev, V., 2004. Sulfur, heat and magma budget of Erta 'Ale lava lake, Ethiopia. Geology $32(6), 509-512$.

Platt, U., Marquard, L., Wagner, T., Perner, D., 1997. Corrections for zenith scattered light DOAS. Geophys. Res. Lett. 24 (14), 1759-1762.

Platt, U., Stutz, J., 2008. Differential Optical Absorption Spectroscopy: Principles and Applications. Springer, Berlin. 
Radke, L., 1982. Chlorine, fluorine, and sulfur emissions from Mount Erebus, Antarctica and estimated contributions to the Antarctic atmosphere. Nature 299, 710-712.

Scorer, R., 1957. Experiments on convection of isolated masses of buoyant fluid. J. Fluid Mech. 2, 583-594.

Sparks, R., Bursik, M., Carey, S., Gilbert, J., Glaze, L., Sigurdsson, H., Woods, A., 1997. Volcanic Plumes. John Wiley and Sons, New-York.

Stevenson, D., Blake, S., 1998. Modelling the dynamics and thermodynamics of volcanic degassing. Bull. of Volcanol. 60, 307-317.

Stoiber, R. E., Jepsen, A., 1973. Sulfur dioxide contributions to the atmosphere by volcanoes. Science 182 (4112), 577-578.

Stoiber, R. E., Malinconico, L., Williams, S., 1983. Use of the correlation spectrometer at volcanoes. In: Tazieff, H. and Sabroux, J.C. (Ed.), Forecasting Volcanic Events. Elsevier Sci., New York, pp. 425-444.

Stutz, J., Platt, U., 1996. Numerical analysis and estimation of the statistical error of differential optical absorption spectroscopy measurements with least-squares methods. Applied Optics 35 (30), 6041-6053.

Sweeney, D., Kyle, P., Oppenheimer, C., 2008. Sulfur dioxide emissions and degassing behavior of Erebus volcano, Antarctica. J. Volcanol. Geotherm. Res. 177, 725-733.

Symonds, R., Gerlach, T., M.H., R., 2001. Magmatic gas scrubbing: implications for volcano monitoring. J. Volcanol. Geotherm. Res. 108, 303-341. 
Torrence, C., Compo, G., 1998. A practical guide to wavelet analysis. Bull. Am. Meteo. Soc. 79 (1), 61-78.

Turner, J., 1979. Buoyancy effects in fluids. Cambridge University Press.

Watson, I., Oppenheimer, C., Voight, B., Francis, P., Clarke, A., Stix, J., Miller, A., Pyle, D., Burton, M., Young, S., Norton, G., Loughlin, S., Darroux, B., Staff, M., 2000. The relationship between degassing and ground deformation at Soufriere Hills Volcano, Montserrat. J. Volcanol. Geotherm. Res. 98, 117-126.

Williams-Jones, G., Horton, K., Elias, T., Garbeil, H., Mouginis-Mark, P., Sutton, A., Harris, A., 2006. Accurately measuring volcanic plume velocity with multiple UV spectrometers. Bull. Volcanol. 68, 328-332.

Wylie, J., Voight, B., Whitehead, J., 1999. Instability of magma flow from volatile-dependent viscosity. Science $285,1883-1885$.

Young, S., Voight, B., Duffell, H., 2003. Magma extrusion dynamics revealed by high-frequency gas monitoring at Soufrire Hills volcano, Montserrat. In: Oppenheimer, C. and Pyle, D.M. and Barclay, J. (Ed.), Volcanic Degassing. Vol. 213. Geological Society, London, Special Publications, pp. 219-230.

Zreda-Gostynska, G., Kyle, P., Finnegan, D., Prestbo, K., 1993. Chlorine, fluorine, and sulfur emissions from Mount Erebus, Antarctica and estimated contributions to the Antarctic atmosphere. Geophys. Res. Lett. 20, 1959-1962. 
Table 1: Symbols used.

$\alpha \quad$ Elevation angle of the lowermost field of view, in deg.

$\theta_{N F O V}$ Narrow angle of aperture of the spectrometers fields of view, in deg.

$\beta \quad$ Angle of separation between the two fields of view, in deg.

$d_{X} \quad$ Long horizontal axis of the field of view at the plume distance, in $\mathrm{m}$.

$d_{Y} \quad$ Vertical distance between the two fields of view at the plume distance, in $\mathrm{m}$.

D Horizontal distance between observation site and plume, in $\mathrm{m}$.

$C C F \quad$ Cross correlation function

$\Delta t \quad$ Time step of the gas column amount series, in s.

$\Delta \tau \quad$ Time resolution of the correlation analysis, in s.

$\Delta T \quad$ Duration of correlation sliding windows, in s.

$t \quad$ Time, in s.

$\tau \quad$ Time shift of the correlation window for the upper spectrometer signal, in s.

$\theta_{W F O V}$ Wide angle of aperture of the spectrometer fields of view, in deg.

Zreda-Gostynska, G., Kyle, P., Finnegan, D., Prestbo, K., 1997. Volcanic gas emissions from Mount Erebus and their impact on the Antarctic environment. J. Geophys. Res. 102 (B7), 15039-15056. 


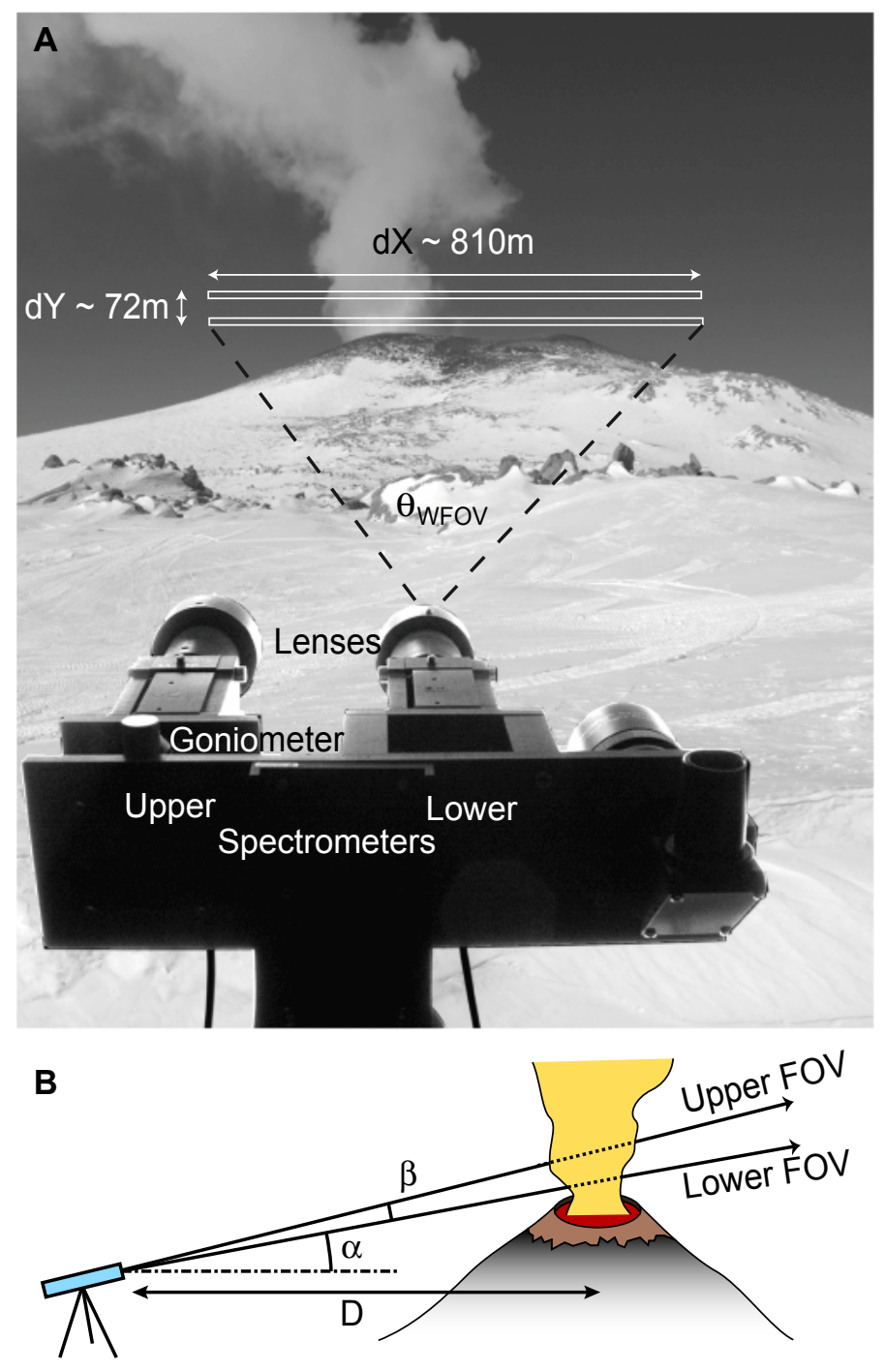

Figure 1: a) Photograph of Erebus volcano from Lower Erebus Hut showing a buoyant plume. Rectangles illustrate the wide fields of view of the two telescopes. Both are linked to UV spectrometers and the angle between the upper and lower fields of view is adjusted using a goniometer. b) Sketch of the geometry of the experiment with symbols used in text. 


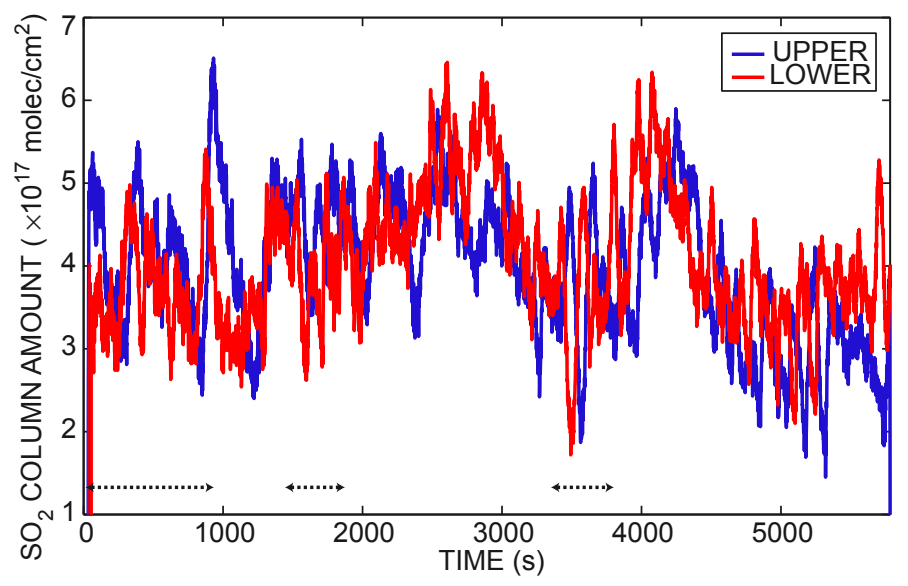

Figure 2: Time-series of $\mathrm{SO}_{2}$ column amounts for both upper (blue) and lower (red) wide field of view spectrometers at Erebus on 26 December 2006 from $\sim 20: 24$ h to 22:02 h UTC. Dashed lines show periods of time when a bend was observable in the plume at a height less than $200 \mathrm{~m}$ above the crater, i.e., below the altitude of the upper spectrometer's FOV. 

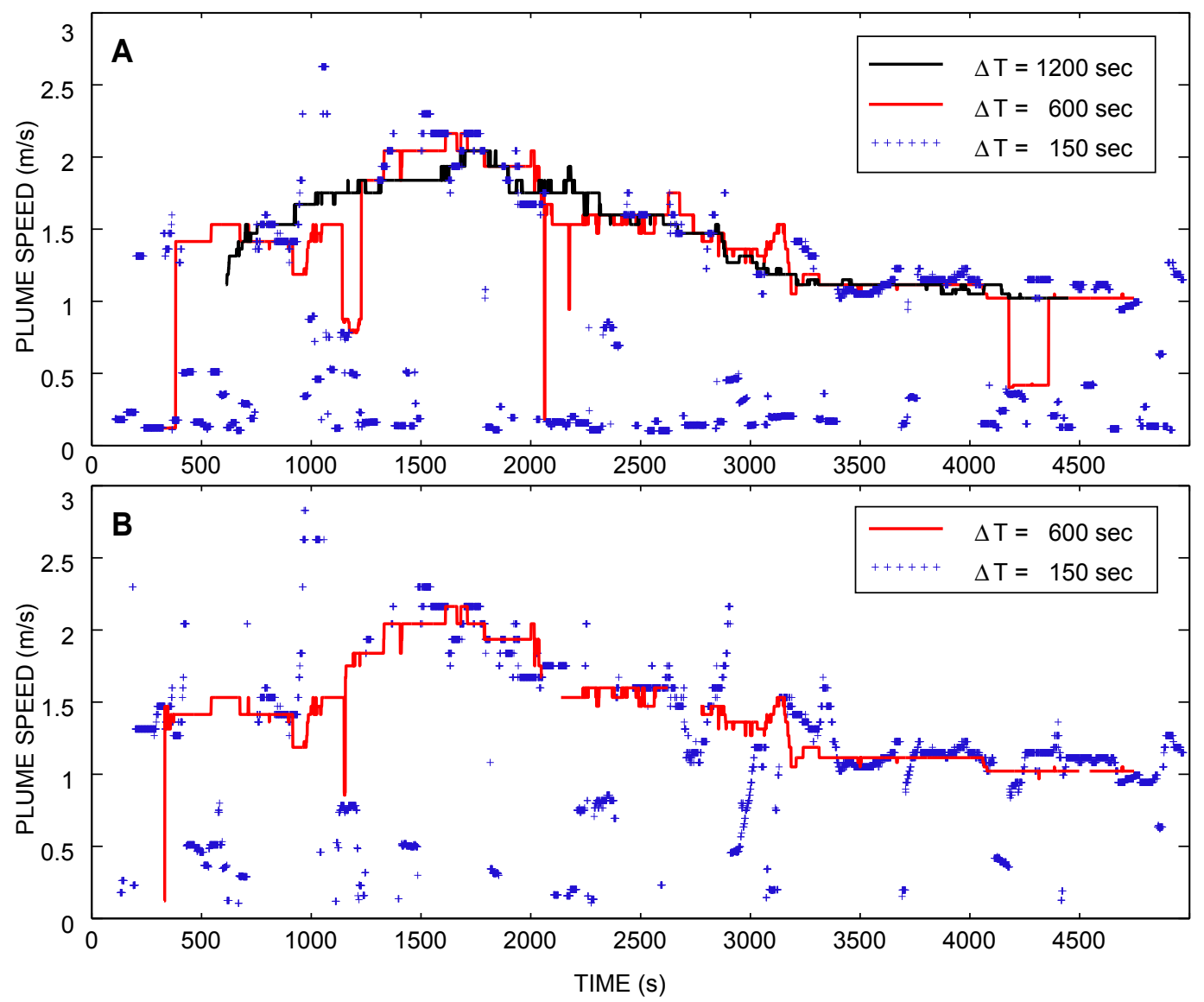

Figure 3: Plume speed vs. time since start of the dataset start at 20:24:48 UTC for (a) different sliding windows used for correlation analysis (with a duration $\Delta T$ of respectively 1200, 600 and $150 \mathrm{~s}$ ), (b) a narrow and long sliding window ( $\Delta T=150$ and $600 \mathrm{~s}$ ), using the criterion selecting the first local maximum in the CCF function, relative to the time shift, with an amplitude above a threshold of 0.5. 


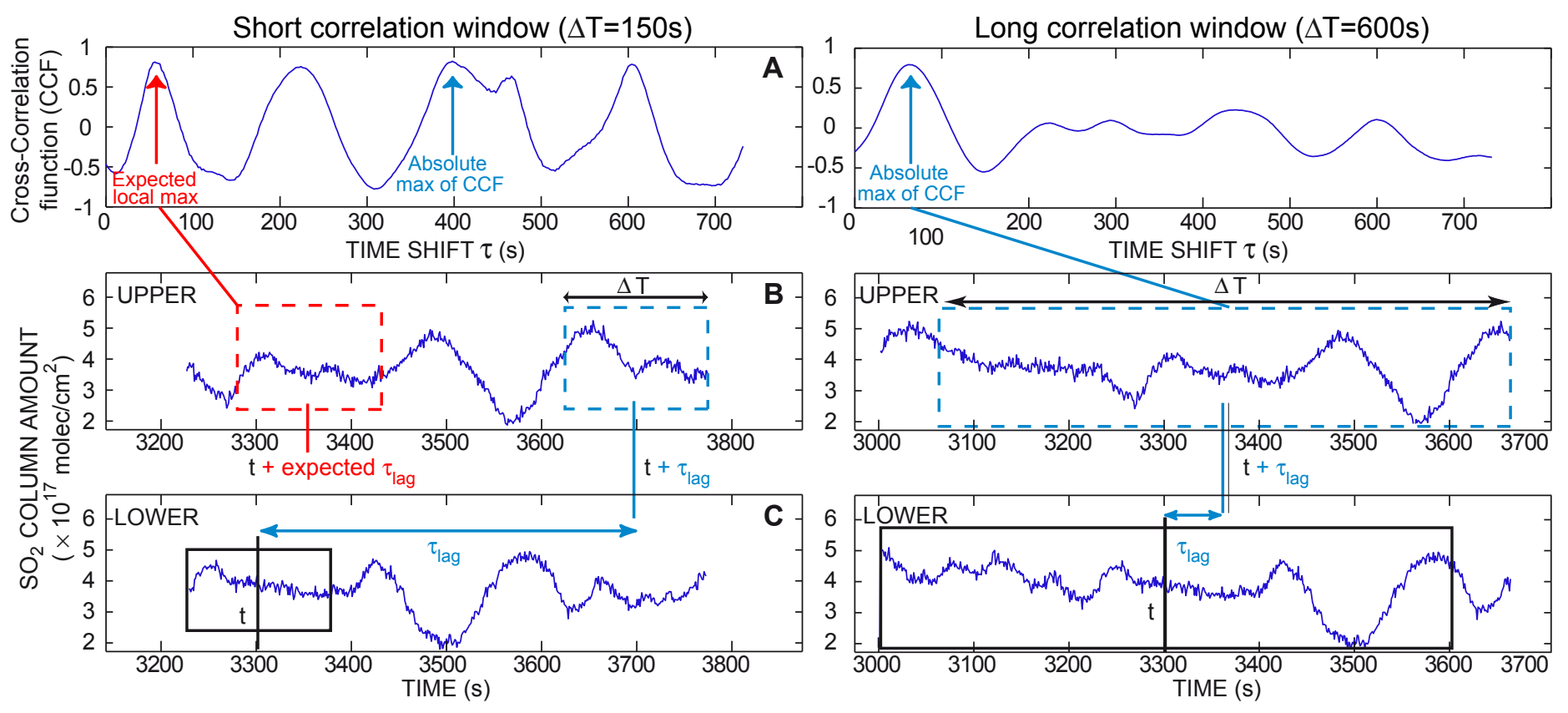

Figure 4: Example of correlation analysis giving a meaningless speed by selecting the absolute maximum (blue) of the cross correlation function (CCF) and not the first local maximum (red). Indeed, using a narrow correlation window of duration $\Delta T=150 \mathrm{~s}$ (on left), the absolute maximum does not correspond to the translation to the second instrument's FOV of the structure inside the lower correlation window, which would give the expected time lag. Rather it matches this initial structure with the translated signal of a similar neighbouring structure. This artifact does not occur with a long window (on right, here $\Delta T=600 \mathrm{~s}$ ) because secondary peaks of the CCF are strongly flattened. (a) Plot of the cross correlation function with the time shit $\tau$ of the upper spectrometer correlation window. (b) and (c) shows signals for, respectively, the upper and lower spectrometers, from $(t-\Delta T / 2)$ up to $\left(t+\tau_{\text {lag }}+\Delta T / 2\right)$, with $\tau_{\text {lag }}$ the obtained time lag. Dashed lines underline correlation windows, centred and fixed in $t$ for the lower spectrometer signal, centred in $(t+\tau)$ for the upper spectrometer signal with $\tau$ increasing until the time lag is found. 

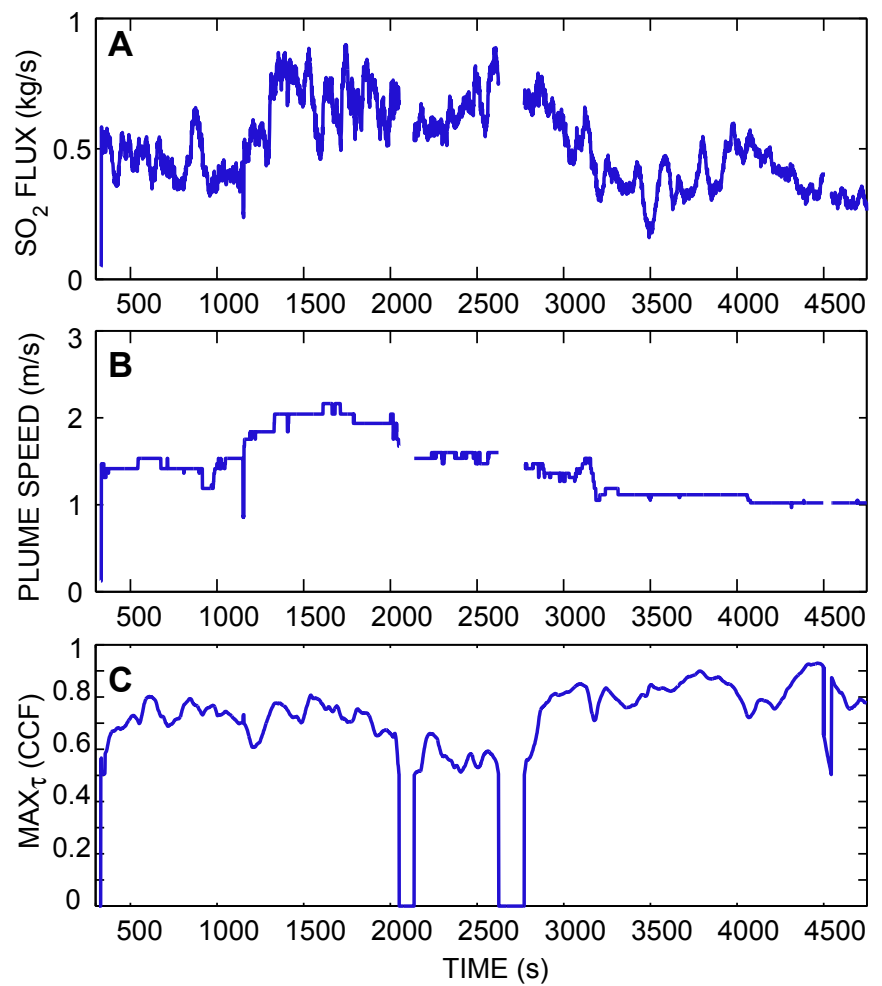

Figure 5: High time resolution (1 s) (a) $\mathrm{SO}_{2}$ flux (in $\mathrm{kg} \mathrm{s}^{-1}$ ) from the lower spectrometer, (b) plume speed (in $\mathrm{m} \mathrm{s}^{-1}$ ), (c) cross correlation coefficient used for plume rise speed estimation fulfilling the two imposed criteria (i.e. corresponding to the first maximum of the cross correlation function with the time shift and which has to exceed a value of 0.5), vs. time from the data set start at 20:24:48 UTC on 26 December 2006, using a 10 min correlation window. Note that the cross correlation coefficient is artificially set to zero when it does not fulfil both required criteria. This results in four gaps in flux data during which speeds cannot be calculated from the correlation analysis. 

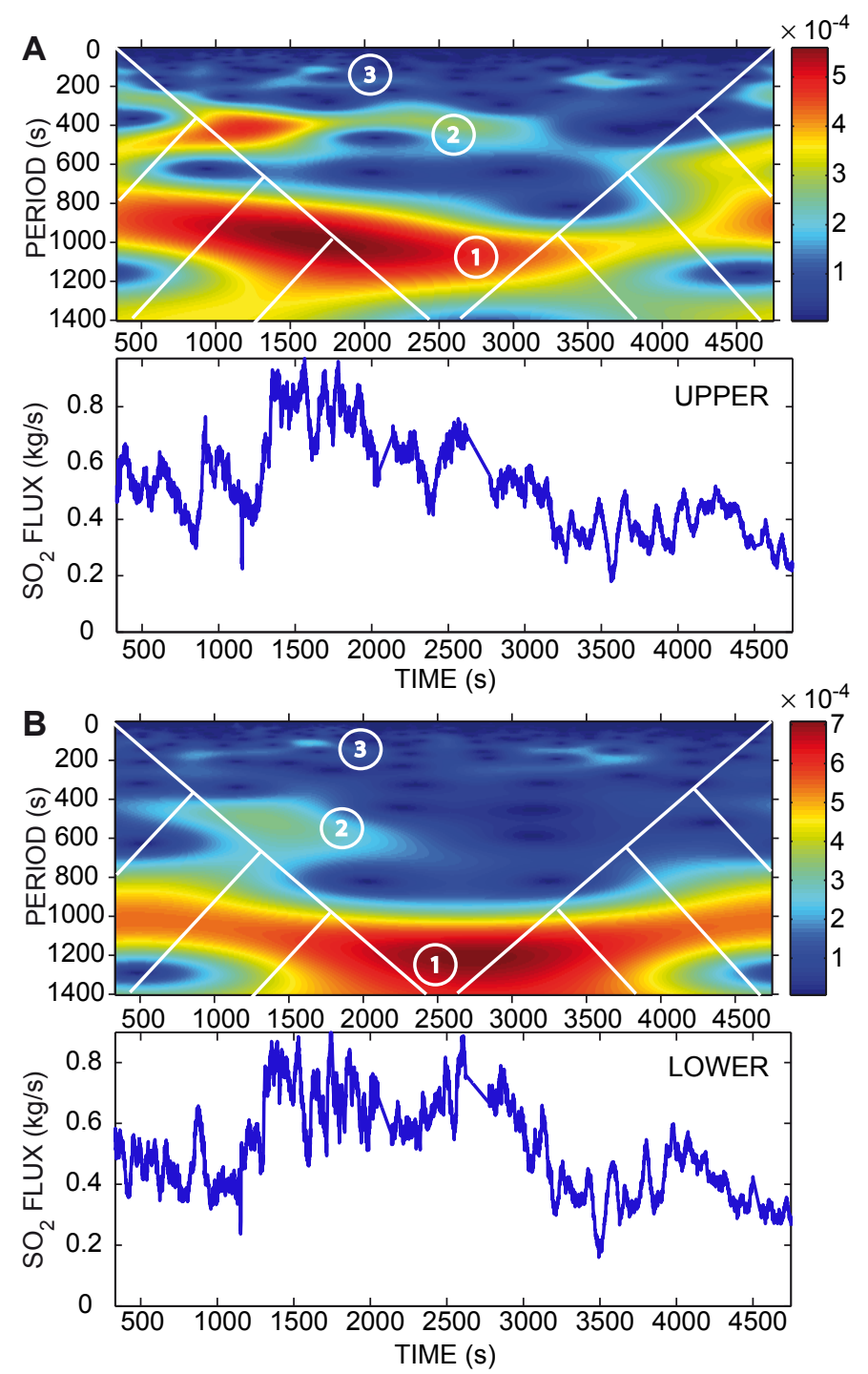

Figure 6: Wavelet transform (modulus) and time-series of $\mathrm{SO}_{2}$ fluxes (in $\mathrm{kg} \mathrm{s}^{-1}$ ) for (a) upper and (b) lower spectrometers. Note that flux time-series are linearly interpolated to fill the few data gaps described in Fig. 5. The three populations of distinctive periods present in the signal (referenced as Patterns 1,2,3 in the figure) are discussed in the text. The cone of influence (white lines) delimits cross-hatched regions, inside which edge effects are non-negligible. 


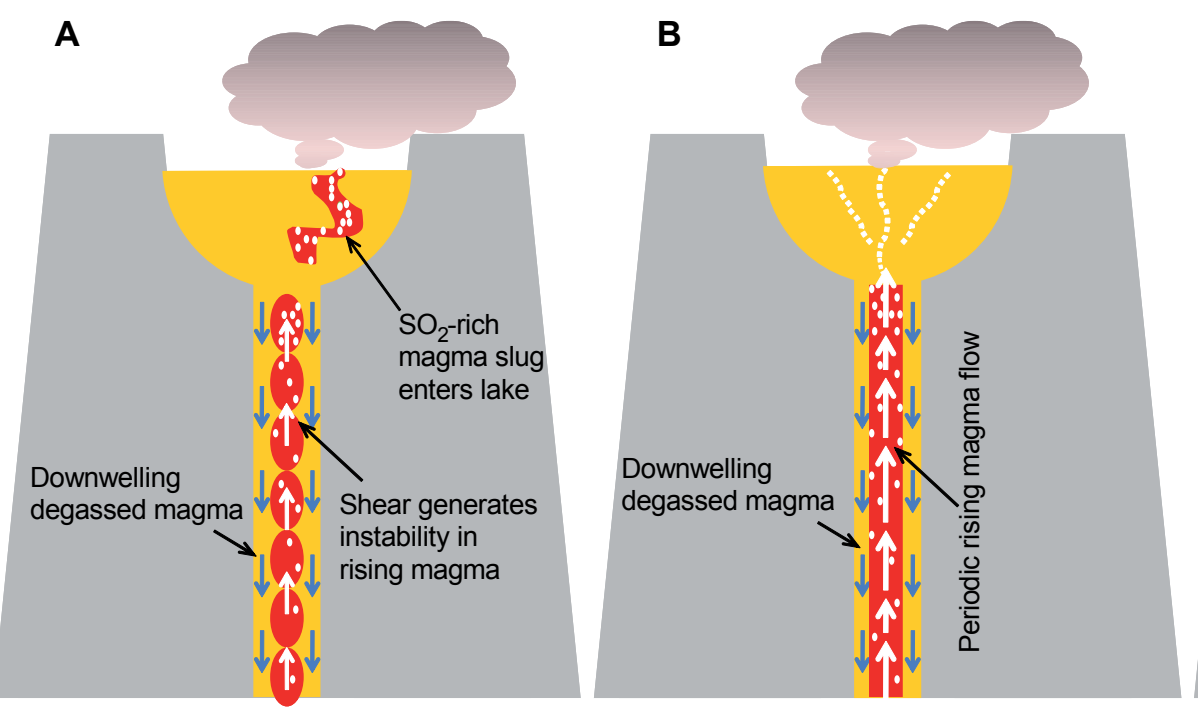

PERIODIC GAS RICH MAGMA SUPPLY

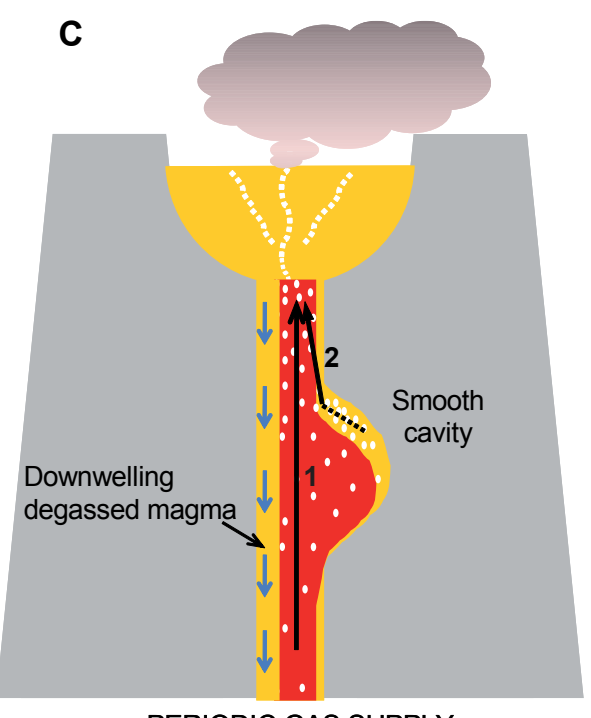

PERIODIC GAS SUPPLY

Figure 7: Cartoon illustrating different processes that can explain periodic degassing. (a) Periodic magma supply to the lava lake as a consequence of boudinage of the ascending magma flow, resulting from shear stresses between the buoyant gas-rich hot rising magma and downwelling cooler degassed counterpart (modified from (Oppenheimer et al., 2009b)); (b) periodic rising magma flow resulting from volatile-dependent viscosity; and (c) periodic gas supply to the lava lake arising from gas segregation in smooth cavities in the conduit. 


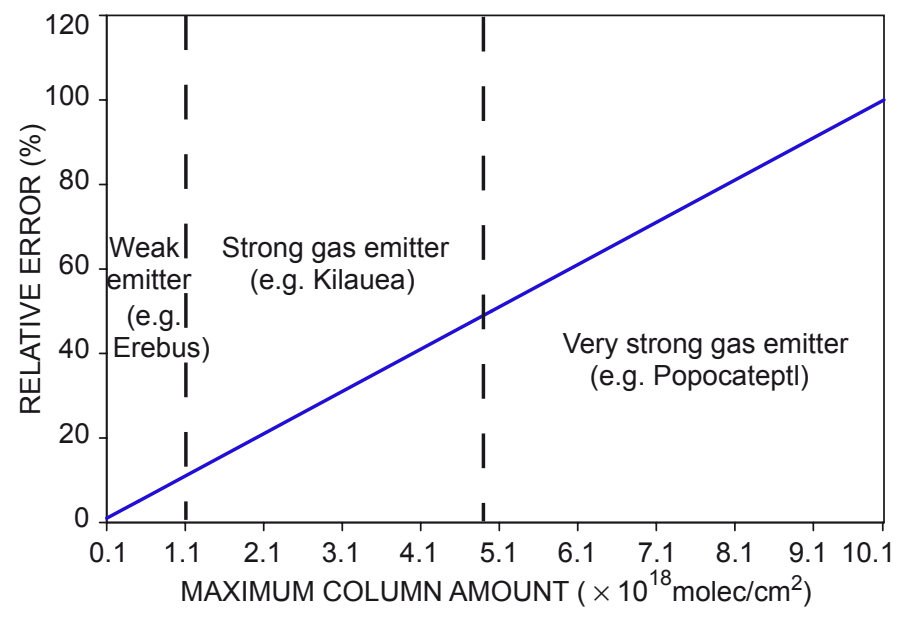

Figure 8: Relative error on the approximation of the mean $\mathrm{SO}_{2}$ column amount $(\overline{C A})$ along the different directions in the wide field of view by the $\mathrm{SO}_{2}$ column amount measured with the DW-FOV DOAS $\left(C A_{W F O V}\right.$ ), according to Eq. A.18 (for more explanations, see Appendix A). For calculations, an averaged value of the $\mathrm{SO}_{2}$ cross section, estimated over the wavelength range used for fit, is considered $\left(10^{-19} \mathrm{~cm}^{2}\right)$. 